\title{
CAUSES OF SPATIAL TRANSFORMATIONS IN RURAL AREAS IN POLAND
}

Jadwiga KONIECZNA, Faculty of Geodesy, Geospatial and Civil Engineering, University of Warmia and Mazury, Olsztyn, Ul. M. Oczapowskiego 10-719 Olsztyn, Poland, jadwiga.konieczna@uwm.edu.pl (corresponding author)

Dariusz KONIECZNY, Faculty of Geodesy, Geospatial and Civil Engineering, University of Warmia and Mazury, Olsztyn, Ul. M. Oczapowskiego 10-719 Olsztyn, Poland, dariusz.konieczny@uwm.edu.pl

Rural areas, defined as land outside towns, except industrial areas, account for over $93 \%$ of the area of Poland. They are attractive as a places of work, residence, leisure, as well as places where agricultural and non-agricultural business activities can be conducted. Agriculture is naturally associated with rural areas. Currently, apart from the agricultural function and (depending on the socioeconomic, natural or historical conditions) rural areas are also places of leisure, recreation, residence or industrial activities. This is a consequence of implementation of the concept of multi-functional development of rural areas, in which conditions are created for diverse business activities, while respecting environmental constraints. Such a multifunctional approach must take into account the interests of all parties to avoid spatial conflicts. Therefore, actions aimed at the development of rural areas should be based on an indepth analysis of the value of the area under consideration, they should take into account natural conditions (soil, climate, terrain) of the land for conducting agricultural activities, but also take into account environmental, social and economic aspects.

Objective and historical conditions affecting agriculture in Poland and the experience gained so far indicate that there is a need to change the spatial arrangement of agricultural areas. This is because of the characteristic features of agriculture in Poland, which include a disadvantageous structure of farms in terms of their area, small size of farms, insufficient technical infrastructure in villages and difficult soil conditions. Rural areas in Poland, including agriculture, are undergoing deep structural changes in regard to agricultural production, but also to farm size and layout, demographic and spatial structures as well as technical and social infrastructure. The changes taking place in rural areas in Poland are greatly affected by the Common Agricultural Policy in the European Union. As a member of the EU, Poland has been receiving aid since 2004 and has been implementing actions within Rural Development Programmes.

The aim of this paper is to analyse the transformations that have been taking place in rural areas in Poland and to present selected factors and causes of the changes in rural spaces.

\section{Keywords: rural areas, rural development, spatial transformations}

\section{INTRODUCTION}

In Poland, rural areas are defined as areas situated outside the administrative boundaries of towns, which means that they make rural communities or rural parts of urban-rural communities. Following the definition quoted above, based on the administrative division (town, village), rural areas account for $93.4 \%$ of the country area and are inhabited by $38.1 \%$ of the total population. The European Union (EU) and the Organisation for Economic Co-operation and Development (OECD) define rural areas on the basis of population density as being below 150 inhabitants per square kilometre. The mean population density in Poland is 122 inhabitants per $\mathrm{km}^{2}$, while in towns this indicator is 1,098 inhabitants per $\mathrm{km}^{2}$, and in rural areas -51 inhabitants per $\mathrm{km}^{2}$. According to such a criterion, rural areas account in Poland for about $91 \%$ of the entire country area. Those areas play a huge role from economic, social and environmental perspectives. The prevailing type of activity conducted in these areas is agriculture and, usually to a lower extent, other forms of economic activities, such as fishery, settlement or tourism.

Rural space has always been subject to changes. The dynamics and directions of those changes have been varied and depended on many factors: the political and economic system of the state, foreign policy - membership in transnational structures, the wealth of the society, popularity of living in a city or at the countryside and the financial condition of the state. System transformations, and even the mere perspective of those changes, had the highest effect on the dynamic of changes in the agricultural areas. Changes in the ownership structure and the farm structure could be observed even before Poland joined the European Union. Currently, the common agricultural policy carried out by the EU has the highest impact on structural changes. It is under this policy that national plans for rural development and related aid programmes are designed, which clearly affects the transformation of rural areas (Kosakowski and Konieczna, 2007). 
The aim of this publication is to analyse selected factors affecting the changes and the development of rural areas in Poland, with particular focus on arranging-agrarian operations.

\section{CHARACTERISTICS OF POLISH RURAL AREAS}

Polish rural areas are highly diversified, both in terms of the development of agriculture, and the possibilities of adopting and implementing changes resulting from contemporary solutions for rural development (Sobolewska-Mikulska, 2009).

Rural areas occupy $93.4 \%$ of the area of Poland, in which arable land accounts for $54.0 \%$, forests - for $28.5 \%$ and permanent grasslands for $11.4 \%$. According to the Agricultural Census of 2002, Poland had 1,956,100 agricultural farms with an area exceeding 1 ha of arable land, in which 1,954,900 agricultural farms belonged to the private sector and 1,200 to the public sector. In 1996-2002, the number of farms decreased by 90,700 farms. In 2002, the average area of a farm exceeding 1 ha of arable land was 9.6 ha.

Although Poland has large resources of agricultural land, the area structure of farms demonstrates high variety and fragmentation. In the structure of agricultural farms in 2002, small farms of an area of $1-5$ ha were the most numerous group and they accounted for more than half (58.7\%) of the total number of farms, using $19.1 \%$ of arable land. The largest farms (above 20 ha of arable land) accounted for only 5.8\%, but they used $34.7 \%$ of the total arable land. The share of average farms ( 5 to 20 ha of arable lands) was 35.5\%, and they used $46.2 \%$ of arable land. The average size of the farm in Poland demonstrates a significant regional differentiation. The highest fragmentation of individual farms is found in southern provinces, where the average arable land area of a farm is 2.56 ha in the Małopolska Province, and 2.83 ha in the Podkarpacie Province. The largest average arable land area is observed for farms in the northern provinces: Warmia and Mazury - 16.65 ha, West Pomerania - 17.57 ha and Pomerania - 12.9 ha (Small Statistical Yearbook, 2002). Most individual farms are arranged in a so-called checker-board pattern, and $18.1 \%$ of them are made of six or more plots. The distance between the plots and the seat of the farm in some cases exceeds even $10 \mathrm{~km}$. The highest fragmentation of agricultural plots is found in farms situated in south-eastern provinces. Environmental and soil conditions in Poland are worse than in other European countries. Light, sandy soils are prevailing here, which to some extent reduces production possibilities. In Poland, there has existed for centuries a very strong tradition of family-run farms and the agriculture has preserved its traditional character. Farms mostly carry out the multidimensional production. The number of people working in agriculture in Poland is significantly higher than in the EU. According to a survey concerning the economic activity of the population, $18 \%$ of the total working population worked in 2002 in agriculture, hunting and forestry sectors. It should be noted that the share of people working in agriculture is decreasing every year, as there are problems with succession in farms and with depopulation of rural areas.

On the other hand, Polish rural areas offer favourable conditions for the development of agritourism, they are strongholds of tradition and culture, where unique natural and landscape values have been preserved. This particularly concerns regions with a low level of industrialization and a low share of employment in non-farming professions. The number of farms providing agritourism-oriented services is systematically growing, although agritourism farms still account for less than $1 \%$ of the total number of farms in Poland.

Serious problems related to rural areas include, e.g. a low degree of specialisation of agricultural farms, which lowers the position of farmers in the market, as well as poorly developed technical infrastructure in the country. This provides one of the most serious barriers for the multifunctional development of rural areas. An unsatisfactory degree of infrastructure development not only lowers the standard of living and farming, but also makes those areas less attractive for investors.

Rural areas in Poland are not free from threats caused by agriculture. Many unfavourable phenomena are observed and the majority of them are a consequence of errors committed in the past, e.g.

- agricultural use of poor and erosion prone soils;

- inefficient water management in agricultural drainage areas;

- a low level of education as regards efficient agricultural practices;

- a failure to provide the farms with the environmental protection infrastructure;

- site contamination of soils with heavy metals.

Additionally, some new threats, related to fallowing of the poorest arable lands, have been emerging recently (Rural Development Plan, 2004).

\section{INSTRUMENTS FOR RURAL DEVELOPMENT}

Development of rural areas is the process of their directional changes, in the course of which they shift from simple forms and states to more complex and improved forms in specific aspects (from the disordered development to sustainable development). Over time, rural areas in Poland have undergone huge transformations.

The rate and directions of rural development areas is affected by a complex set of factors, including (Niedzielski E., Rzeszutek J. 2010):

- historical and cultural conditions, which shaped, among others, the area structure of farms, network of settlements, rural architecture, relation to traditions and introduction of changes, etc.;

- political factors, which can be clearly seen after the change of the political system in Poland, the effect of national and common European agricultural policy; 
- technological and production changes related to the use of chemicals, mechanization and computerization of processes, biological progress, changes in manufacturing processes;

- natural factors related to the quality and the role of the natural environment and geographical factors concerning spatial location, features of the landscape or land forms;

- social and demographic factors concerning population density, occupational structure, the level of education and living standard.

A particular role in the transformation dynamics in rural areas is performed by agricultural policy of the state and the system of impact of state authorities on the development of agriculture and rural areas. The instruments for rural development at the disposal of state authorities may include:

- organisational and legal instruments: objectives of regional policy, including the concept of eco-friendly farming, planning studies in the commune;

- prohibitions, orders and restrictions: restrictions concerning the location of environmentally harmful investments, proper management in hazard zones, restrictions concerning transformations of arable land and farmland conversion;

- financial instruments: fees for excluding the land from agricultural use, agricultural and forest tax, tax on business units that are harmful to the environment;

- information and education instruments: consulting, education concerning sustainable development.

Principles governing agriculture changed when Poland joined the European Union, i.e. on May 1, 2004. The system of state authorities controlling the development of agriculture was replaced with solutions applied in the EU. A system of area payments was introduced, covering all farmers. The Rural Development Plan and the Sectoral Operational Programme were introduced supporting the restructuring and modernization of the food production sector.

The aim of rural development as an element of the common agricultural policy in the EU countries is to reduce traditional forms supporting the agriculture in order to satisfy new social expectations concerning additional functions of agriculture, such as: caring for the natural environment, maintaining the landscape or culture of villages and rural areas (Sobolewska-Mikulska, 2009).

\section{ARRANGING-AGRARIAN OPERATIONS AS TOOLS FOR RURAL DEVELOPMENT}

An improvement in the organization of rural production space and modernization of rural areas is carried out mainly through arranging-agrarian operations. Those works include technical and organizational procedures, taking into account natural, economic, legal and social conditions of a given area, including, e.g. land consolidation, modernization and construction of access roads leading to arable land and modernization or construction of other technical infrastructure installations, reclamation and fertilization of arable lands, preventing soil erosion.

Analysing the development of arranging-agrarian operations, which to a various degree affected the changes in the spatial structure of rural areas and their development, it is possible to distinguish several stages.

Stage I - covers post-war years; this period is characterized, among others, by such works as: land exchange, land expropriation, sale and lease of land of the State Land Fund (PFZ), transferring the land owned by the State Land Fund to state and cooperative units, carrying out uniform land classification and scarce consolidation works. Some of those works already contain certain elements of spatial-management improvements of land use conditions (e.g. consolidations).

Stage II - was carried out mainly in 1970s and 1980s. The main aim of works performed at that time was to improve spatial and economic condition of land use, made mainly through: consolidation and replacement of land, adjustment of the communication structure, improvement of the production capacity of land, land protection and development of construction and technical infrastructure. Those works were, in most cases, performed at various times and on various objects, therefore, they were not fully effective, e.g. consolidation operation were performed first and followed by land melioration works, which resulted in the creation of the so-called "secondary" checker-board pattern as drainage ditches additionally crossed the plots.

Stage III - took place in 1980s and 1990s. The idea behind the operations at this stage was to manage rural areas in a comprehensive manner. The arranging-agrarian operations, depending on the natural conditions of the given area, the degree of its development and dynamics of the social and economic development and land concentration, included: maintenance and improvement of the natural conditions (e.g. meliorations, transformation of arable land) works aimed at preventing unfavourable phenomena (e.g. anti-erosion protection, establishing windproof belts), restoring devastated and not agriculturally used areas for use, mapping out and establishing new boundaries or regulating the existing boundaries of developed areas, transformation of the ownership and use structure; construction of new and redevelopment of the existing agricultural transport roads.

Stage IV - present, began in 2004, i.e. with the access of Poland to the European Union, when Polish agriculture and rural areas were covered by the EU Common Agricultural Policy mechanisms and the development of rural areas received the support of the EU funds. The structure of aid programmes has a significant impact on changes taking place in agriculture and in the rural areas, according to the principles of sustainable development. Farming and rural areas are subsidized from two coherent and mutually supplemented programmes: the Rural Development Plan (RDP) and the Sectoral Operational Programme "Restructuring and Modernisation of the Food Sector and Rural Development" (SOP). The RDP already implemented for 2004-2006 supported the farm modernization processes, and assumed the following directions:

1. Increasing economic efficiency of farms with early retirement, supporting small scale farms, groups of agricultural producers; 
2. Achieving equality of opportunities for rural development by supporting agricultural activities in less-favourable farming conditions;

3. Protection of the environment and maintaining the natural values of rural areas.

4. Expanding the forest cover of Poland by afforestation of agricultural land.

The operations carried out under this programme were oriented towards economic aspects; they provided a great opportunity for small farms with low potential, often situated in areas requiring protection.

Another document affecting the direction for support and development of rural areas was the RDP developed for 2007 2013. Operations under this programme were oriented towards:

1. Improvement of the competitiveness for the agricultural and forestry sector through vocational training for persons employed in agriculture and forestry.

2. Improvement of the natural environment and rural areas through support for farming in mountain areas and other less-favoured areas, payments for the Natura 2000 areas and areas affected by the introduction of the Framework Water Directive, agricultural and environmental payments, afforestation of agricultural land and others.

3. Improvement of the quality of life in rural areas and diversification of rural economy through diversification into non-agricultural activities and establishment and development of micro-enterprises, renewal of villages.

The above mentioned operations included also a new initiative - LEADER, the aim of which was to activate rural communities by developing local development strategies for areas preserving cultural and natural heritage of villages. Under the RDP 2007-2013 activities, a great emphasis was put on operations related to the improvement of the environment. This mainly concerns operations related to farming in mountain areas, areas of unfavourable farming conditions and the Natura 2000 areas.

Currently, the RDP for 2014-2020 is being implemented. As results from the experience concerning performance of specific operations, some changes with regard to the principles for implementing certain aid instruments and their better adjustment to farmers' needs are necessary. Therefore, attempts have been made to adjust the operations carried out under RDP 2014-2020 addressed to farmers, agricultural producers and inhabitants of rural areas to respond to their needs and expectations. The priority of the Programme is to improve the competitiveness of the agricultural sector, while taking into account the climatic and environmental objectives. First of all, further restructuring and modernization of farms and development of the agricultural and food processing industry will be supported. Implementation of operations planned in this regard will allow farmers and entrepreneurs to meet the increasingly competitive challenges in the European market and in external markets (Rural Development Programme for 2014-2020).

Looking from the time perspective at the administrative-agrarian operations carried out, a change can be observed in the scope of works performed and the manner in which those works were approached by administrative authorities responsible for their implementation and the inhabitants of rural areas. In the first period, each of the activities undertaken was carried out separately, which was ineffective in achieving the full desired social and economic effect. Currently, those procedures are performed in an organized manner, taking into account environmental and economic conditions, to facilitate reaching comprehensively designed aims of the rural development.

At present, arranging-agrarian procedures in Poland should be aimed at (Witkowska, 2016):

- improvement of life and work conditions for the rural population and increasing the income of the rural population,

- marked improvement of the agrarian structure,

- solving conflicts related to land use,

- minimizing land loss for non-farming purposes,

- prospective regional and local development and renewal of villages,

- implementing objectives concerning environment and landscape protection and water management,

- improving rural infrastructure,

- increasing the value of the region, and therefore making it more attractive, enhancing the economic and business strength of farms and rural areas.

Considering objective and historical conditions for the Polish agriculture and based on previous experience, it can be observed that the spatial system of rural areas requires further changes. As regards the implemented procedures, a significant role in this process has been played by land consolidation processes, carried out for years. They provide the main instrument and a stimulus for rural development, which means integrated activities leading to an increase in attractiveness of the areas in the economic, social, ecological, landscape and spatial aspects. Land consolidation is a classic legal solution, aimed at complex improvement of conditions for farming and forestry operations. This complex and time-consuming procedure results in obtaining well-formed plots with a convenient access. A new design of the communication system in the village can make access to plots easier and shorten the distance between the settlement and the farming plots, and in effect, production costs are lowered, and labour expenditure and fuel consumptions are reduced. At the stage of market economy, this is of particular importance for enhancing the competitiveness of agricultural production. The diversity of aspects covered by the consolidation project ensures the multifunctional development of a given rural area.

\section{CONCLUSION}

Rural areas play a huge role in the spatial and economic structure of Poland. Transformations occurring in these areas are caused by various factors of internal and external nature. Those factors have interpenetrated over time with varied intensity. In the case of Polish villages, an additional factor includes changes related to transformation of a 
centrally-controlled economy into a free market economy. This shift towards the free market resulted in an increasing number of village inhabitants being involved in trade, service or craft activities using the own resources of their farms.

Particularly intensive changes occurring in rural areas in Poland are the consequence of the membership in the European Union and implementation of the common agricultural policy. Those changes are reflected, among others in (Niedzielski E., 2015):

- a reduced role of agriculture - a decreasing share of agriculture in GDP and in employment structure, a reduced arable land area and a lower number of farms;

- an increased role of non-farming business activities - an increase in forest coverage rate and functions related to forestry, development of agritourism, growth of craft activities and use of local resources;

- growing importance of the environmental function - increased environmental awareness, concern for biodiversity, landscape architecture, improvement of the environmental quality (soil, water, air);

- increasing importance of social and cultural functions - development of settlements in the country, development of technical and social infrastructure, increased involvement of local communities.

Extending the Common Agricultural Policy (CAP) to Polish farmers and implementing specific programmes with the use of structural funds resulted in assigning higher financial means to agriculture and rural areas than in the past. Poland became one of the largest beneficiaries of the CAP. This brought about huge structural and organizational changes in those areas. Examples of those changes include:

- an increase in the area of agricultural farms and their economic strength,

- improvement of the income situation of farmers and countryside dwellers,

- an increase in the number of business units operating in rural areas,

- an increase in the number of villages with water and sewage systems or gas networks,

- improvement of the social infrastructure conditions (access to educational establishments, cultural institutions),

- increased areas of ecological interests and development of eco-friendly agriculture,

- strengthening the position of Poland as an important European food producer.

Rural development should be based first of all on strategic thinking about the sustainable development of the country, territorial cohesion and optimum use of resources offered by Polish villages. Enhanced participation of rural communities and joint efforts make an important condition for the adjustment to the new situation and challenges in the market.

Based on the analysis, it can be concluded that since 2004, the common agricultural policy (CAP) instruments have had the greatest impact on transformations in Polish agriculture. This is the direct payments and activities aimed at the modernisation of farms that have the strongest effect, and help increase the competitiveness of agriculture and the income of the population employed in this sector. It should be borne in mind, however, that rural areas, being connected with agriculture, need specific strategies and the cooperation between various actors: from government and local government institutions to the agricultural population. The measures taken need to take into consideration, inter alia, the satisfactory level of the agricultural population's income, the prevention of environmental degradation, and the adjustment of the food production growth rate to the demand.

\section{REFERENCES}

1. Cohesive Structural Policy for Rural Areas and Agriculture Development. Document approved by the Council of Ministers in 1999, Poland.

2. Kosakowski J., Konieczna, J. 2007. Role of the spatial data infrastructure in implementing the Common Agricultural Policy. Zeszyty Naukowe Akademii Rolniczej w Krakowie, Vol. 23, pp. 55-60. [In Polish]

3. Niedzielski E., Rzeszutek J. 2010. Rural development in former state-owned farm areas. Roczniki Naukowe SERiA t. XII, Vol. 5. [In Polish]

4. Niedzielski E. 2015. Functions of rural areas and their development. Zagadnienia Ekonomi Rolnej, Vol. 2, pp. 84-93. [In Polish]

5. Rural Development Programme for 2014-2020. Ministry of Agriculture and Rural Development. Poland 2016.

6. Small Statistical Yearbook. Central Statistical Office, Warsaw 2002.

7. Sobolewska-Mikulska, K. 2009. Methodology of rural development with the focus on selected surveying procedures in the aspect of integration with the European Union. Prace Naukowe, Geodezja, Vol. 44, pp. 12-25. [In Polish]

8. Witkowska E., 2016: Improved organization of agricultural production space using arranging-agrarian procedures - presentation. WBGiTR. Available at http://wbgitr.nazwa.pl/wp4/download-attachment/879 (Accessed on 17/10/2017) 